\title{
Moving towards a competency-based curriculum: Analyses of patients' information and students' evaluation in geriatric and special care dentistry
}

Nareudee Limpuangthip

Chulalongkorn University Faculty Of Dentistry

Orapin Komin ( $\triangle$ Orapin.geriatric@gmail.com )

Chulalongkorn University Faculty Of Dentistry https://orcid.org/0000-0001-6831-9382

Teerawut Tatiyapongpaiboon

Thungyai Hospital

Research article

Keywords: oral condition, curriculum, postgraduate, geriatric dentistry, elderly

Posted Date: September 3rd, 2020

DOI: https://doi.org/10.21203/rs.3.rs-40860/v2

License: (c) (i) This work is licensed under a Creative Commons Attribution 4.0 International License.

Read Full License 


\section{Abstract}

Background: There is no core competency for geriatric dentistry and special patient care (GSP) in Thailand. Therefore, a GSP program was developed as a knowledge-based curriculum. The purpose of this study was to describe the development and architecture of the GSP curriculum by analysing information of the patients attending the GSP clinic and students' evaluation to move towards a competency-based curriculum. Comparisons with the original GSP curriculum and future direction are discussed.

Methods: The development and architecture of the GSP curriculum were described. Information of the 130 patients attending the GSP clinic, and those who participated in a maintenance recall was analysed. Students' evaluation was performed using a questionnaire comprising 21 items within 7 domains based on the ASEAN University Network-Quality Assurance (AUN-QA) checklist. The responses were made using a 5-point ordinal scale ranging from totally agree to totally disagree.

Results: Only $50 \%$ of the patients attended a maintenance recall to be assessed for their oral and general health. Among the recalled patients, $74.2 \%$ reported emerging problems. The AUN-QA questionnaire responses indicated that students mostly agreed with the program specification, teaching and learning approach, students' assessment methods, student quality, and support domains. Indifferent reactions were predominantly on the expected learning outcomes, a clear contribution of each course, timely student feedback, academic staff quality, and output domains. The modified curriculum was developed based on the patients' information and students' evaluation. The original and modified GSP curricula were compared.

Conclusions: Information analysis of the patients and students' evaluation are essential to move a knowledge-based curriculum for geriatric and special patient care dentistry towards a competency-based curriculum that is appropriate for the patients' condition and serve students' requirements. Oral health care in elderly and special care patients requires a multidisciplinary approach, and should encompass oral disease problems, behavior and social context.

\section{Background}

Due to health care and socioeconomic improvement, the elderly population is projected to grow worldwide, especially in developing countries [1,2]. Highly developed countries in Asia, such as Korea, Singapore, and China are shifting towards an aged population. Thailand is also moving in the same direction [3]. Since 2005, Thailand has become an aging society where elderly individuals (60 years-old and above) account for $10 \%$ of the total population, and will be moving towards a super-aged society in 2050 with a $35 \%$ elderly population [4].

Chronic or non-communicable diseases are a major cause of disability and mortality, especially in the elder population. The presence of underlying diseases affects their ability to maintain proper oral hygiene, and also lead to oral diseases [5]. Similar to the elders, a group of adolescents or adults, classified as 
special care patients, is unable to perform routine dental care due to physical, medical, intellectual, psychological, or social impairment [6]. Thus, delivering oral health care to elderly and special care patients is a concern for dental professionals.

Due to the complexity of dental treatment and patient management, some dental professionals lack confidence to provide appropriate oral health care to special care and elderly patients [7].Moreover, some elderly patients and family caregivers perceive that there are inadequate geriatric dentistry specialists and services [8].Therefore, the inclusion of geriatrics within dental curricula has been the subject of consideration worldwide [9].To date, postgraduate geriatric dentistry programs have been developed in several countries, such as the United States of America [10],European countries [11], and Japan [12]. Furthermore, special care dentistry education is typically provided by the pediatric department [13].

Despite the rapidly increasing number of elderly people, Thai dental students are not well-prepared to provide oral health care for this age group. In 2005, the Thai Ministry of Public Health launched a national oral health plan for elderly Thai people with an aim to improve their oral health and quality of life [14]. One of the strategies was to motivate all dental schools to develop a geriatric dental curriculum at the undergraduate and postgraduate levels, as well as a short-term training program.

Currently, all 13 dental schools in Thailand offer series of lectures in geriatric dentistry as a 1-credit course for $5^{\text {th }}$ or $6^{\text {th }}$ year dental students. The overall learning outcomes are to describe oral health care in elderly people and to explain the scope of geriatric dentistry. Eight dental schools provide a separate and independent program for postgraduate students in geriatric dentistry, including clinical training and oral health promotion programs [15]. In 2016, the Faculty of Dentistry at Chulalongkorn University established the first Master's program entitled "Geriatric Dentistry and Special Patients Care" (GSP); with a goal to be a learning center of oral health care for geriatric and special care patients in South-East Asia. The GSP program is the only international program in Thailand that collaborates with Chulalongkorn University medical school and Tokyo Medical and Dental University (TMDU) in Japan. The program targets elderly patients with complex medical conditions and younger adults who need special care.

There is currently no core competency for geriatric dentistry and special patient care in Thailand. Therefore, the original GSP program was developed as a knowledge-based curriculum by adopting the academic contents related to geriatric dentistry from several Japanese dental schools, because the present elderly situation in Japan is expected to be the future of Thailand. Meanwhile, the need for oral health care was estimated based on secondary data from Thai people $[4,16,17]$. Three years into the program, the original curriculum has been modified based on the patients' information and students' evaluation. This transformation leads the GSP program towards a competency-based curriculum, which is student-centered and adaptive to the changing needs of students, patients, and society.

The purpose of this study was to describe the development and architecture of the GSP curriculum by analysing information of the patients attending the GSP clinic and students' evaluation to move towards 
a competency-based curriculum. The comparisons with the original GSP curriculum and future direction are discussed.

\section{Methods}

The original GSP program was developed in 2016. The curriculum development started by determining the need for oral health care in Thai people using the Thai national oral health surveys [16], the 2014 survey of the older persons in Thailand [4], and a basic database of a previous study in our dental school [17], as well as the school potential. The curriculum was then established beginning with the learning outcomes, learning contents, teaching and learning accessibility, and students' evaluation method. In 2019, the GSP curriculum was modified based on public agency requirements, using the patients' information and students' evaluation. The curriculum architecture of the GSP program, collection of patients' information, and students' evaluation are described in the following subsection.

\section{Curriculum architecture of GSP program}

The curriculum architecture is defined by 4 domains; 1 ) program of the study, 2) authentications, 3 ) teaching and learning accessibility, and 4) business model variables. The descriptions are:

\section{Programs of Study:}

\section{1) Degree taxonomy and Certificate}

The Geriatric and Special Patients Care program offers a postgraduate degree of Master of Science (M.Sc.) in Geriatric Dentistry and Special Patients Care (International program).

\section{2) Expected learning outcomes}

The expected learning outcomes of the GSP program are;

- To be able to evaluate and justify the oral health condition of elderly and special care patients.

- To be able to create a rational dental treatment plan for elderly and special care patients, and modify the plan if needed.

- To be able to provide a suitable oral health care and dental treatment for elderly and special care patients.

- To be able to design and produce a project to solve specified problem in elderly and special care people.

\section{3) Curricular options and Minimum requirement}

Two curricular options are available for students who enroll the GSP program; Plan A, thesis only, and Plan B, thesis and coursework. For each option, the applicants can choose whether to be a distance- or 
non-distance learner. Non-distance learners physically participate in all classes and clinical practice at the GPS clinic, whereas the distance learners attend classes through an online learning platform, and physically participate in classes and the GSP clinic at least one week per month. The curricula options and their minimum passing requirements are shown in Table 1.

The GSP curriculum consists of 40 credits with three major contents; 1 ) the academic core courses in gerontology and geriatric dentistry and special need patients, and dental research (20\%), 2) clinical courses where they perform diagnosis, design rationale treatment plans, and patient management (50\%), and 3 ) research related to elderly and special care patients (30\%).

\section{4) Academic duration}

The GSP curriculum offers a bi-semester two-year program. The core and clinical courses are completed within the two years, with a maximum of 4 years depending on a research extension.

\section{5) Entry requirements}

The entry requirements for domestic applicants are [18]: 1) having graduated with a bachelor's degree in Doctor of Dental Surgery (DDS) from an accredited dental school, 2) having a Thai dental license from the Thai Dental Council, 3) having at least 1 year working experience, and 4) having the required English test score. If the applicant is not a dentist, he/she can apply for Plan A (thesis only).

The entry requirements for international applicants is similar to those of domestic applicants. Applicants need to be able to speak and read Thai language to perform clinical practice, otherwise, they can apply only for Plan A (thesis only) [18].

\section{Authentications}

The patients, students, and academic staff are responsible for an internal quality assessment of the GSP program. The patients and their guardians can rate their satisfaction level and give additional comments via a Google form by scanning a QR code available at the GSP clinic. The students and academic staff can evaluate each course at the end of the semester via the Chulalongkorn University-Curriculum Administration System, an online university system. At the end of each academic year, 3 external experts including a curriculum specialist, a dental hospital delegate, and a dental specialist from another department discuss the available information obtained from patients', students', and instructors' evaluation results.

For external quality assessment, the two public agencies responsible for the dental clinic and curriculum accreditation of the GSP program are the Healthcare Accreditation Institute (HAl) and the Office of the Higher Education Commission (OHEC), respectively. The HAI promotes the standard and quality of healthcare organizations across Thailand. The OHEC is an accreditation agency that oversees the country's universities and other higher education institutions at the undergraduate and graduate levels. 
Based on the OHEC standard, Chulalongkorn University requires that the 2-year curriculum be revised at least once every 3 years.

\section{Teaching and learning accessibility}

The two teaching methods in the original GSP curriculum are classroom-based learning (lectures, paper discussion, case-based) and clinical training (in the GSP clinic and off-site). In the clinical course, the students provide comprehensive dental treatment for the patients attending the clinic under the supervision of experienced dental staffs. During a summer course prior to the second year; the students can attend a geriatric dentistry short course at the collaborating Japanese dental school for 2 weeks (optional).

\section{Business model variables}

The GSP income is from the tuition fee (40\%) and dental treatment profit (60\%). Human resources comprise academic staff (85\%) and support staff (15\%). In the original curriculum, academic staff comprise dental staffs, medical staffs from Chulalongkorn medical school, and staffs at the off-site (TMDU in Japan). Nurses, nutritionists, pharmacologists, and off-site staff at nursing homes and elderly/community clubs were also included in the modified GSP curriculum. The support staff comprise dental assistants and one administrative staff.

\section{Collection of patients' information}

The patients attending the GSP clinic were classified into 2 groups with the following eligibility criteria: 1) elderly patients ( $\geq 70$ years old) with a medically complex condition, or functionally dependent with a 4 (vulnerable) to 9 (terminally ill) clinical frailty score [19], and 2) younger patients (<70 years old) who have a physical, medical, sensory, intellectual, mental, emotional, or social disability, or a combination of these conditions, with a less than 80\% Karnofsky Performance Score [20].

During 2016-2019, 130 patients received comprehensive dental treatment at the GSP clinic for at least 6 months. The comprehensive dental treatment consisted of 6 phases: 1) systemic phase (medical consultation), 2) emergency phase (any dental procedures to reduce pain or discomfort, such as tooth extraction or emergency endodontic or periodontal treatment), 3) disease control phase (dental caries control, oral hygiene instruction, and behavior management), 4) preparatory phase (surgical, operative, endodontic, and periodontal treatment), 5) rehabilitation phase (dental prosthesis), and 6) maintenance phase.

Not all patients enrolled in the rehabilitation phase. Enrollment depended on the individual's physical and psychological condition, treatment needs, oral health insurance, and family support. The GSP clinic provided a one-stop service where patients could receive all types of dental treatment. The exceptions were dental treatment under general anesthesia and some surgical treatments, such as bony exostosis 
removal or implant placement. These cases were treated in the operating room by an oral surgeon. One dental unit is available for patients requiring emergency treatment such as dental pain or a broken tooth.

The patients' information was collected from hospital records: socio-demographic status, oral condition, type of dental treatment, and health conditions. The patients' oral conditions were clinically examined, including the number of remaining natural teeth and posterior occluding pairs. The types of dental treatment comprised operative (filling, dental caries prevention), periodontal (scaling, root planning), endodontic (root canal treatment, pulp treatment), prosthodontic (fixed and removable dentures), and oral surgery treatment (tooth extraction, implant placement).

The patients' health conditions were categorized into types of diagnosed systemic disease and dependency status. The dependency status of the dental patients in our clinic was classified into 3 levels based on the Chinese-Canadian study of health and aging clinical frailty scale physician version [19]: 1) independent (very fit, well, or well-controlled), 2) semi-dependent (vulnerable, or mildly frail), and 3) dependent (moderately frail, or severely frail). The need for a caregiver in performing daily activities was recorded (need, no need).

The patients were called to invite them for a maintenance recall visit. The patients attending the recall visit had their general health and oral conditions reassessed. Any oral- and denture-related problems reported by the patients were recorded.

\section{Students' evaluation}

During 2016-2019, there were 24 students in the GSP program. In 2019, students' evaluation of the original GSP program was performed by sending an online questionnaire (Google form) to all students. Informed consent was obtained from the students, and their responses were confidential and were not linked to their identity.

The questionnaire comprised 21 items within 7 domains based on the Asian University Quality Assessment (AUN-QA) checklist [21]: 1) expected learning outcomes, 2) program specification, 3) program structure and content, 4) teaching and learning approach, 5) student assessment, 6) academic staff quality, 7) support staff quality, 8) student quality and support, 9) facilities and infrastructure, 10) quality enhancement, and 11) output. The response was made using a 5-point ordinal scale ranging from totally agree $($ score $=5)$ to totally disagree $($ score $=1)$. Open-ended questions were available for students to give comments on each domain.

\section{Data analyses}

Data analyses were performed using the IBM Statistics Package for the Social Sciences (SPSS) version 22.0. Descriptive statistics was used to calculated the percentage (\%) of patients' information according each variables and students' evaluation. 


\section{Results}

\section{Patients' information}

From 2016-2019, 130 patients attended the GSP clinic. Table 2 presents the characteristics of the patients who received comprehensive dental treatment from the GSP students and those attending a maintenance recall. The patients were $78.0 \pm 10.7$ years old (mean $\pm S D$ ), ranging from 18-95 years, mostly residing in Bangkok. Evaluating the patients' oral conditions revealed that $85-90 \%$ had less than 20 remaining teeth and less than 4 posterior occluding pairs. Their dental treatment needs were predominantly dental prostheses. The prevalence of special care conditions in the younger patients were $5 \%$. Approximately $40 \%$ of the patients needed a care giver to assist them in their daily activities.

Out of 130 patients, 28 patients could not be contacted and 11 had passed away. After a telephone invitation, 29 patients refused to attend a periodic dental check-up due to the following reasons: having more serious physical impairments $(n=18)$, moving to another clinic/hospital because they were dissatisfied with the denture fabricated at the GSP clinic $(n=7)$, and migrating to other provinces $(n=4)$. Among the 62 patients who attended a maintenance recall visit at the GSP clinic, $74.2 \%$ reported emerging problems mainly gingival or oral tissue irritation/inflammation (30.7\%), dental caries or dislodged restoration (29.0\%), or an ill-fitting denture (11.3\%). The patients' interview responses indicated that the recall patients had not received dental care elsewhere because a dental unit is available in case of emergency treatment during the recall period.

\section{Students' evaluation}

There were 5-7 students per year in the GSP program, either working in public hospitals (80\%) or private clinics (20\%). The students' response rate was $87.5 \%$. Table 3 demonstrates the two most frequent answers on the 21-items AUN-QA questionnaire. Students mostly agreed with the program specification, teaching and learning approach, students' assessment methods, student quality and support domains. The indifference reactions were predominantly on the expected learning outcomes, a clear contribution of each course, timely student feedback, academic staff quality, and the output domains. The highest agreement (71.4-85.7\%) was the comprehensive and up-to-date curriculum and program. From the additional comments, $25 \%$ of the students requested more clinical experience and management in patients with complex physical and psychological conditions, as well as home-bound and bed-bound patients. They also desired more off-site experiences and experienced healthcare staff in addition to dental specialists.

\section{Comparisons between the original and modified GSP program}


Based on the patients' information and students' evaluation of the original GSP program, the modified GSP curriculum was developed. The comparisons between the original and modified GSP curriculum are demonstrated in 7 aspects (Table 4): curricular options, entry requirements, academic content, teaching and learning methods, learning sites, academic staff, and student evaluation.

\section{Discussion}

The original GSP program was developed for postgraduate students as a knowledge-based curriculum that aimed to increase clinical experience in managing elderly and special care patients. As shown in the learning outcomes, more advanced competencies are expected: the application, analysis, synthesis, and evaluation levels, compared with the geriatric dentistry course for undergraduate students, of which the outcomes are limited to the knowledge and comprehensive levels [22]. After the program had been in operation for 3 academic years, the original curriculum was revised according to the OHEC standard, and the modified GSP curriculum was developed based on the patients' information and students' evaluation. The modified GSP program moves towards a competency-based curriculum because it serves patient's condition and students' requirements. More learning activities and environments have been created for the students to apply their knowledge, skills, and attitudes to the situations they commonly encounter [23].

In the modified GSP program, distance learning is available as one of the curricular options. It was created especially for dentists in rural areas who have to work while studying, and to increase accessibility to continuing education for dentists in rural areas. In addition to the face-to-face learning, the original classroom-based learning is provided on online platforms, such as Google meet and Zoom meeting, which is allowed for distance learning.

Despite adopting the academic content from Japanese dental school, different aspects affect the strategies of the original GSP program. Elderly Thai people are eligible for two health insurance schemes; $\sim 80 \%$ for the Universal Health Coverage Scheme (UCS) and the others for the Civil Servant Medical Benefit Scheme (CSMBS) [24]. Both schemes provide benefit packages for dental care without cost at government health facilities, including periodontal treatments, fillings, extraction, and acrylic-based removable dentures. Only the CSMBS includes endodontic treatment, and some fixed prostheses (crown and bridge), but with a limited reimbursement rate. Therefore, tooth loss and a need for removable denture are commonly found in elderly Thai people, rather than saving the teeth. Although geriatric dentistry in Japanese dental schools emphasizes the importance of oral disease prevention and oral health promotion, the original GSP program focused on tooth replacement and oral rehabilitation for elderly patients. The finding indicates that the curriculum development might be influenced by individual patients' condition, their social context, and government policy.

The patients' information indicated that $75 \%$ of the patients receiving maintenance recalls had emerging oral health problems. Moreover, many patients had more serious health conditions leading to poorer oral self-care or swallowing difficulty. In addition to oral rehabilitation, the modified GSP curriculum focuses 
more on the behaviour management of uncooperative patients, oral disease prevention, and other oral care with adjunctive materials and special instruments. Dietary consultation and nutritional assessment should become a part of oral health care in the GSP clinic. In the modified curriculum, the one-credit core course in community dentistry has been changed from a classroom-based learning to off-site learning, allowing the students to develop an oral health promotion project for elderly and special patients. We expect that the modified course will enable the students to design and produce a project to solve a specified problem in elderly and special care people as stated in the expected learning outcomes.

In the original GSP program, both physicians and dental professionals were responsible for classroombased learning. Physicians provide lecture courses based on their specialties, but do not participate in a clinical section. Our results indicated that most patients attending the GSP clinic were elderly who had several complex non-communicable diseases. According to the students' evaluation, the original curriculum already provides extensive lectures on systemic diseases of the elders, but does not provide sufficient knowledge and clinical skill to manage special care patients as proposed in the learning outcome. In addition, the GSP students commented on the lack clinical experience in managing dependent and frail elders because the GSP clinic at the dental faculty is independently located from a medical hospital. Dependent elderly and special care patients, registered at a hospital, are generally referred to the hospital dental department when dental treatment is needed. Therefore, the modified GSP curriculum provides more information on special care conditions, ranging from degenerative diseases to genetic disorders. By reducing the clinical hours in the GSP clinic and moving to the off-site, students would have a greater opportunity to engage in various special care centers and experienced staffs in medical institutions, hospitals for disabled people, nursing homes, and community hospitals.

\section{Limitations}

Some limitations were noted in the present study. First, the AUN-QA questionnaire was developed for students, staff, and stakeholders to evaluate the curriculum. However, the staffs' and stakeholders' evaluations were not analyzed in the present study. Thus, the results obtained only from the students' evaluation may have occurred due to the students' lack of information, e.g. certain academic staff quality and support staff quality aspects. The students may not know whether the performance management, including rewards and recognition, have been implemented for the staff, and thus give low scores to these aspects. Second, students' evaluation of the modified program has not yet been performed.

\section{Future directions}

Currently, the GSP students provide all types of dental treatment in the GSP clinic, except for complex endodontic treatment, oral surgery, and sedation, as stated in the present learning outcome. However, performing comprehensive treatment may not be possible in the near future when the number of elderly and special care patients increase. The learning outcome should be modified in the future such that the students will provide the appropriate oral health care, but not all types of dental treatment. The future 
curriculum will result in the GSP clinic being a one-stop service center that includes students from several departments to reduce fragmented care. The GSP students will be responsible for assessing, conducting, and organizing dental treatment plans. They will act as a coordinator in communicating and encouraging family members, caregivers, and the healthcare team to form a holistic care approach. Didactic geriatric content needs to be integrated into all relevant clinical departments that deal with elderly patient care.

Despite residing in Bangkok, more than half of the patients did not receive regular maintenance care. In accordance with other studies [24,25], a major obstacle in oral health care accessibility is due to the patient's functional limitations and lack of family or care giver support. Some caregivers are unable to evaluate the oral condition or provide basic oral health care [26]. Students need to be provided additional clinical chair-time to provide basic oral health care knowledge and skills for patients and their caregivers. In conjunction with the medical school, a certified caregiver training program should be developed and include oral health care aspects to improve health attitudes and oral health literacy. An active approach for oral disease prevention and oral health promotion should be conducted through home visits, mobile dental units, and teledentistry. Using advanced communication technologies, we believe that teledentistry would benefit for elderly individuals who have difficulty in accessing oral health care by providing them dental consultations and oral health care advice [27].

In the future, the evaluation of the modified GSP curriculum should include the present students' evaluation, academic and supportive staff, the faculty, alumni, and the stakeholders. Following the AUNQA guideline [21], the evaluations framework covers: 1) the process input, including academic and support staff, student quality and support, and facilities and infrastructure, 2) the quality enhancement of the program, including curriculum design and development, teaching and learning, student assessment, quality of support services and facilities, and stakeholders' feedback, and 3) the program output, including pass rates and dropout rates, the average time to graduate, employability of the graduates, research activities and stakeholders' satisfaction, 4) the achievements of the expected learning outcomes, and 5) the fulfilment of the stakeholders' needs and continuous improvement of the quality assurance system and benchmarking.

The findings from the GSP program were data from an urban Thai dental school where patient characteristics and their needs could be different from those in rural areas. Further study is recommended to comprehensively review the geriatric curriculum in provincial Thai dental schools to develop core competency in geriatric dentistry postgraduate program.

\section{Conclusions}

The present study demonstrated the development and architecture of the curriculum in geriatric and special patients care dentistry. The original program was developed as a knowledge-based curriculum. To further program development, information analysis of the patients and students' evaluation are essential to move the program towards a competency-based curriculum that is appropriate for patients' condition 
and serve the students' requirements. Oral health care for elderly and special care patients requires a multidisciplinary approach, and should encompass oral disease problems, behavior, and social context.

\section{List Of Abbreviations}

AUN-QA, ASEAN University Network-Quality Assurance; GSP, geriatric and special patient care; HAl, Healthcare Accreditation Institute; M.Sc., Master of Science; OHEC, Office of the Higher Education Commission.

\section{Declarations}

\section{Ethics approval and consent to participate}

The study protocol was approved by the International Review Board Committee of the Faculty of Dentistry, Chulalongkorn University (HREC-DCU 2018-112) and was performed in accordance with the 2013 Declaration of Helsinki. Written informed consent was received from the students and the patients or a family member who was their legal guardian.

\section{Consent for publication}

Not applicable

\section{Acknowledgements}

The authors acknowledge the Geriatric and Special Patients Care clinic, Faculty of Dentistry, Chulalongkorn University, for providing a location to collect data. We gratefully acknowledge Dr. Kevin Tompkins for language revision of the manuscript.

\section{Availability of data and material}

The datasets used and/or analysed during the current study are available from the corresponding author on reasonable request.

\section{Competing interests}

The authors declare that there are no competing interests.

\section{Funding}

None

\section{Authors' contribution}

$\mathrm{NL}$ and OK contributed to the study conception and design, data acquisition, analysis, and interpretation, writing and revising of the article, and final approval of the version to be published. TT contributed to the 
data acquisition, data analysis and interpretation, revising of the article, and final approval of the version to be published.

\section{Authors' information}

Nareudee Limpuangthip is currently a lecturer at the Department of Prosthodontics at Chulalongkorn University, Bangkok, Thailand. She holds a PhD in prosthodontics from Chulalongkorn University. Her research interests are in the field of prosthodontics and geriatric dentistry, and how to improve the oral health and quality of life of elderly people.

Orapin Komin is currently a lecturer at the Department of Prosthodontics at Chulalongkorn University, Thailand. She holds a PhD in prosthodontics from Tokyo Medical and Dental University in Japan. She is the founder and director of the Geriatric Dentistry and Special Patients Care program of the dental school. Her research interests are in the field of geriatric dentistry and prosthodontics.

Teerawut Tatiyapongpaiboon is currently a dentist at Thungyai Hospital, Nakhon Si Thammarat, Thailand. He holds a Master Degree in Geriatric Dentistry and Special Patients Care (International Program) from Chulalongkorn University.

\section{References}

1. Broadbent JM, Zeng J, Foster Page LA, Baker SR, Ramrakha S, Thomson WM. Oral health-related beliefs, behaviors, and outcomes through the life course. J Dent Res. 2016;95(7):808-13.

2. Shrestha LB. Population aging in developing countries. Health Affairs. 2000;19(3):204-12.

3. World Population Prospects - Population Division. United Nations. 2019. Accessed June 2020.

4. Report on the 2014 survey of the older persons in Thailand. National Statistical Office. 2014.

5. Petersen PE, Yamamoto T. Improving the oral health of older people: the approach of the WHO Global Oral Health Programme. Community Dent Oral Epidemiol 2005;33(2):81-92.

6. Definition of Special Health Care Needs. Pediatr Dent 2016;38(6):16.

7. Ferguson FS, Berentsen B, Richardson PS. Dentists' willingness to provide care for patients with developmental disabilities. Spec Care Dentist 1991;11(6):234-237.

8. Paley GA, Slack-Smith L, O'Grady M. Oral health care issues in aged care facilities in Western Australia: resident and family caregiver views. Gerodontology 2009;26(2):97-104

9. Slack-Smith LM, Hearn L, Wilson DF, Wright F. Geriatric dentistry, teaching and future directions. Aust Dent J 2015;60 Suppl 1:125-130

10. Ettinger RL, Goettsche ZS, Qian F. Postdoctoral Teaching of Geriatric Dentistry in U.S. Dental Schools. J Dent Educ 2017;81(10):1220-1226

11. Kossioni A, McKenna G, Muller F, Schimmel M, Vanobbergen J. Higher education in Gerodontology in European Universities. BMC Oral Health 2017;17(1):71. 
12. Kitagawa N, Sato $\mathrm{Y}, \mathrm{Komabayashi} \mathrm{T}$. Graduate and undergraduate geriatric dentistry education in a selected dental school in Japan. Eur J Dent Educ 2011;15(4):231-235.

13. Sherman CM, Anderson RD. Special needs education in Canadian dental school curriculum: is there enough? J Can Dent Assoc 2010;76:a11.

14. The 2nd national oral health plan for the Thai elders 2005-2022. Bureau of Dental Health. 2005.

15. The 2 nd meeting of the collaboration for better oral health of older Thai people. Bureau of Dental Health. 2020.

16. The 7th national oral health report 2011. Report No. 2018-09-11. Bureau of Dental Health. 2011.

17. Youdying W. The characteristics of elderly patients seeking care at faculty of dentistry, chulalongkorn university during 2007-2009 and the development of dental service electronic database for the aged. Bangkok: Chulalongkorn University, 2011. MS thesis.

18. Faculty of Dentistry, Chulalongkorn University. Geriatric Dentistry. http://www.dent.chula.ac.th/geriatric/index.php. Accessed 20 August 2020.

19. Rockwood K, Song X, MacKnight C, Bergman H, Hogan DB, McDowell I, et al. A global clinical measure of fitness and frailty in elderly people. Can Med Assoc J 2005;173(5):489-495.

20. Peus D, Newcomb N, Hofer S. Appraisal of the Karnofsky Performance Status and proposal of a simple algorithmic system for its evaluation. BMC Med Inform Decis Mak 2013;13:72.

21. Asian University Network quality assurance. Guide to AUN-QA assessment at programme level. version 3.0. 2015.

22. Bloom BS. Taxonomy of educational objectives: the classification of educational goals. Handbook 1 : Cognitive domain. White Plains, N.Y.: Longman. 1956.

23. Chambers DW. Toward a competency-based curriculum. J Dent Educ 1993;57(11):790-793.

24. Limpuangthip N, Purnaveja S, Somkotra T. Predisposing and enabling factors associated with public denture service utilization among older Thai people: a cross-sectional population-based study. BMC Oral Health 2019;19(1):220.

25. Montini T, Tseng TY, Patel H, Shelley D. Barriers to dental services for older adults. Am J Health Behav 2014;38(5):781-788.

26. Komin O, Weerapol P. Oral Health Status of Patients with Dementia and their Caregivers' Ability in Oral Health and Dysphagia Assessment: A Pilot Study. J Dent Assoc Thai 2020;70(1):1-10.

27. Jampani ND, Nutalapati R, Dontula BS, Boyapati R. Applications of teledentistry: A literature review and update. J Int Soc Prev Community Dent 2011;1(2):37-44.

\section{Tables}

Table 1. The curricula options and minimum requirement of the GSP program. 


\begin{tabular}{|c|c|c|c|}
\hline & \multirow{2}{*}{$\begin{array}{l}\text { Plan A: Thesis } \\
\text { only } \\
\text { (distance and } \\
\text { non-distance } \\
\text { learners) } \\
\end{array}$} & \multicolumn{2}{|c|}{ Plan B: Thesis and Coursework } \\
\hline & & Non-distance learners & Distance learners \\
\hline Courses & Thesis (40 cr.) & $\begin{array}{l}\text { 1. Thesis }(12 \mathrm{cr} .) \\
\text { 2. Core courses }(8 \mathrm{cr} .) \\
\text { 3. Clinical courses }(18 \mathrm{cr} \text {.) } \\
\text { 4. Elective courses }(2 \mathrm{cr} .)\end{array}$ & $\begin{array}{l}\text { 1. Thesis }(12 \mathrm{cr} .) \\
\text { 2. Core courses }(8 \mathrm{cr} .) \\
\text { 3. Clinical courses }(18 \mathrm{cr} .) \\
\text { 4. Elective courses }(2 \mathrm{cr} .)\end{array}$ \\
\hline $\begin{array}{l}\text { Minimum } \\
\text { passing } \\
\text { requirements }\end{array}$ & $\begin{array}{l}\text { One } \\
\text { international } \\
\text { publication }\end{array}$ & $\begin{array}{l}\text { 1. Manuscript submission for conference } \\
\text { proceeding, or one local or international } \\
\text { publication } \\
\text { 2. Cumulative grade of at least B. } \\
\text { 3. Reports of at least } 8 \text { comprehensive } \\
\text { cases ( } \geq 6 \text {-month follow-up duration), } \\
\text { done at GSP clinic }\end{array}$ & $\begin{array}{l}\text { 1. Manuscript submission for conference proceeding, or one local } \\
\text { or international publication } \\
\text { 2. Cumulative grade of at least B. } \\
\text { 3. Reports of at least } 8 \text { comprehensive cases ( } \geq 6 \text {-month follow-up } \\
\text { duration), at least } 2 \text { are done at GSP clinic and the others at the } \\
\text { affiliated hospitals }\end{array}$ \\
\hline
\end{tabular}

cr., credits.

Table 2. Characteristics of all patients and those who attended a maintenance recall. 


\begin{tabular}{|c|c|c|}
\hline \multirow[t]{2}{*}{ Variables } & All patients $(\mathrm{N}=130)$ & Patients receiving a maintenance recall visit $(\mathrm{N}=62)$ \\
\hline & $\%$ & $\%$ \\
\hline \multicolumn{3}{|c|}{ Socio-demographic characteristics } \\
\hline Age: $<65$ years & 4.6 & 3.2 \\
\hline $65-74$ & 20.8 & 25.8 \\
\hline $75-84$ & 49.2 & 51.6 \\
\hline$\geq 85$ & 25.4 & 19.4 \\
\hline Sex: Male & 43.1 & 46.8 \\
\hline Female & 56.9 & 53.2 \\
\hline Work status: Not working & 86.2 & 82.3 \\
\hline Currently working & 13.8 & 17.7 \\
\hline \multicolumn{3}{|l|}{ Main source of living expenses: } \\
\hline Themselves (assets, passive income) & 19.2 & 17.7 \\
\hline Family & 69.2 & 71.0 \\
\hline Both & 11.6 & 11.3 \\
\hline Residential area: Bangkok & 84.6 & 82.3 \\
\hline Not Bangkok & 15.4 & 17.7 \\
\hline \multicolumn{3}{|c|}{ Oral conditions } \\
\hline Number of remaining teeth: $<20$ & 85.4 & 88.7 \\
\hline$\geq 20$ & 14.6 & 11.3 \\
\hline Posterior occluding pair: $<4$ & 87.7 & 90.3 \\
\hline$\geq 4$ & 12.3 & 9.7 \\
\hline \multicolumn{3}{|c|}{ Type of dental treatment } \\
\hline Prosthodontic & 93.1 & 96.8 \\
\hline Periodontal & 68.5 & 79.0 \\
\hline Operative & 60.8 & 67.7 \\
\hline Endodontic & 6.9 & 8.1 \\
\hline Oral surgery & 29.2 & 25.5 \\
\hline \multicolumn{3}{|c|}{ Health condition } \\
\hline \multicolumn{3}{|l|}{ Dependency status: } \\
\hline Independent & 66.9 & 69.4 \\
\hline Semi-dependent & 16.9 & 19.4 \\
\hline Dependent & 16.2 & 11.3 \\
\hline \multicolumn{3}{|l|}{ Diagnosed underlying disease: } \\
\hline High BP & 57.7 & 56.5 \\
\hline Diabetes mellitus & 27.7 & 29.0 \\
\hline High cholesterol & 34.6 & 50.0 \\
\hline Cardiovascular diseases & 29.2 & 40.3 \\
\hline Kidney disease & 5.4 & 8.1 \\
\hline Lung disease & 3.8 & 3.2 \\
\hline Osteoporosis & 10.8 & 16.1 \\
\hline Cancer & 3.1 & 4.8 \\
\hline Parkinson's disease & 5.4 & 6.5 \\
\hline Dementia & 11.5 & 11.3 \\
\hline \multicolumn{3}{|l|}{ Care giver: } \\
\hline No need & 54.6 & 59.7 \\
\hline Need & 45.4 & 40.3 \\
\hline
\end{tabular}


Table 3. Students' evaluation of the GSP program following the AUN-QA questionnaire.

Page $17 / 20$ 
(\%)

Indifferent Agree Totally

1. Expected Learning Outcomes

1.1) Clearly formulated and aligned with the vision and university mission

$33.3 \quad 57.1$

1.2) Cover both subject specific and generic learning outcomes

$42.9 \quad 38.1$

1.3) Clearly reflect the requirements of the stakeholders

42.9

33.3

2. Program Specification

2.1) Comprehensive and up-to-date information of the program

71.4

2.2) Comprehensive and up-to-date information of the course

85.7

2.3) Communicated and available to the stakeholders

$42.9 \quad 28.6$

3. Programme Structure and Content

3.1) Designed based on constructive alignment with the expected learning outcomes

$33.3 \quad 47.6$

3.2) Clear contribution made by each course to achieve the expected learning outcomes

$47.6 \quad 33.3$

3.3) Logically structured, sequenced, integrated and up-to-date

14.3

66.7

4. Teaching and Learning Approach

4.1) Well-articulated and communicated educational philosophy to all stakeholders

$23.8 \quad 52.4$

4.2) Constructively aligned to the achievement of the expected learning outcomes

19.0

66.7

4.3) Enhance life-long learning

52.4

5. Student Assessment (timeline, methods, regulations, weight distribution, rubrics and grading)

5.1) Constructively aligned to achieve the expected learning outcomes

$33.3 \quad 52.4$

5.2) Explicit and communicated to students

$28.6 \quad 33.3$

5.3) Use rubrics and marking schemes to ensure validity, reliability and fairness

5.4) Feedback of student assessment is timely and helps to improve learning

$42.9 \quad 28.6$

5.5) Students have ready access to appeal procedure

6. Academic Staff Quality

6.1) Carrying out academic staff planning (considering succession, promotion, redeployment, termination, and retirement) to fulfil the needs for education, research and service

6.2) Measuring and monitoring staff-to-student ratio and workload to improve the quality of education, research and service

6.3) Determined and communicated recruitment and selection criteria including ethics and academic freedom for appointment, deployment and promotion

6.4) Identified and evaluated competences of academic staff

6.5) Identified training and developmental needs of academic staff, and implemented activities

$38.1 \quad 33.3$

6.6) Implemented performance management including rewards and recognition to motivate and support

$\begin{array}{ll}47.6 & 23.8\end{array}$
education, research and service

6.7) Established, monitored and benchmarked types and quantity of research activities by academic staff for improvement

\section{Support Staff Quality}

7.1) Carried -out support staff planning (at the library, laboratory, IT facility and student services) to fulfil the needs for education, research and service

7.2) Determined and communicated recruitment and selection criteria for appointment, deployment and promotion

7.3) Competences of support staff are identified and evaluated

7.4) Identified and implemented training and developmental needs of support staff are identified and activities are implemented to fulfil them

7.5) Implemented performance management including rewards and recognition to motivate and support education, research and service

8. Student Quality and Support 
8.1) Well-defined, communicated, published, and up-to-date student intake policy and admission criteria

8.2) Determined and evaluated methods and criteria for the selection of students are

8.3) Adequate monitoring system for student progress, academic performance, and workload

8.4) Available academic advice, co-curricular activities, student competition, and other student support services to improve learning and employability

8.5) Conductive physical, social and psychological environment for education, research, and personal wellbeing

9. Facilities and Infrastructure

9.1) Adequate and updated teaching and learning facilities and equipment

$33.3 \quad 42.9$

9.2) Adequate and updated library and its resources

9.3) Adequate and updated laboratories and equipment

9.4) Adequate and updated IT facilities including e-learning infrastructure

9.5) Defined and implemented standards for environment, health and safety; and access for people with

special needs

10. Quality Enhancement

10.1) Stakeholders' needs and feedback serve as input to curriculum design and development

10.2) Established curriculum design and development process, and subjected to evaluation and enhancement

10.3) Continuously reviewed and evaluated teaching and learning processes and student assessment to ensure their relevance and alignment

10.4) Using research output to enhance teaching and learning

10.5) Quality of support services and facilities (at the library, laboratory, IT facility and student services) subjected to evaluation and enhancement

10.6) Systemic stakeholder's feedback mechanisms, and subjected to evaluation and enhancement

11. Output

11.1) The established, monitored and benchmarked pass rates and dropout rates

$57.1 \quad 28.6$

11.2) The established, monitored and benchmarked average time to graduate

$57.1 \quad 19.0$

11.3) The established, monitored and benchmarked employability of graduates

$52.4 \quad 23.8$

11.4) The established, monitored and benchmarked types and quantity of research activities by students

$38.1 \quad 28.6$

11.5) The established, monitored and benchmarked satisfaction levels of stakeholders

$47.6 \quad 23.8$

Table 4. Comparison between the original and modified GSP curriculum. 


\begin{tabular}{|c|c|c|}
\hline & Original & Modified \\
\hline $\begin{array}{l}\text { Curricular } \\
\text { option }\end{array}$ & Only non-distance learners & Non-distance and distance learners \\
\hline $\begin{array}{l}\text { Entry } \\
\text { requirements }\end{array}$ & $\begin{array}{l}\text { Graduated dentist with at least } 1 \text { year } \\
\text { working experience. }\end{array}$ & $\begin{array}{l}\text { - Graduated dentist with at least } 1 \text { year working experience. } \\
\text { - Applicants for 'thesis only' option can be graduates from any bachelor } \\
\text { degree. }\end{array}$ \\
\hline $\begin{array}{l}\text { Academic } \\
\text { content }\end{array}$ & $\begin{array}{l}\text { Common underlying disease in elderly } \\
\text { people }\end{array}$ & $\begin{array}{l}\text { More content in genetic disorders, immunodeficiency diseases, common } \\
\text { underlying disease in special need patients, and diet and nutrition }\end{array}$ \\
\hline $\begin{array}{l}\text { Teaching and } \\
\text { learning } \\
\text { methods }\end{array}$ & $\begin{array}{l}\text { - Lecture, paper discussion } \\
\text { - Face-to-face learning }\end{array}$ & $\begin{array}{l}\text { - Lecture, paper discussion } \\
\text { - Case-based learning, problem-based learning } \\
\text { - Oral health promotion and disease prevention project } \\
\text { - Observers in medical school } \\
\text { - Face-to-face and online learning }\end{array}$ \\
\hline Learning sites & $\begin{array}{l}\text { - GSP clinic } \\
\text { - Medical school } \\
\text { - TMDU dental school }\end{array}$ & $\begin{array}{l}\text { - GSP clinic } \\
\text { - Medical school } \\
\text { - TMDU (optional) } \\
\text { - Nursing home, elderly/community club }\end{array}$ \\
\hline Academic staff & Physicians and dentists & $\begin{array}{l}\text { - Physicians and dentists } \\
\text { - Nurse, physical therapist } \\
\text { - Nutritionist } \\
\text { - Pharmacologist }\end{array}$ \\
\hline $\begin{array}{l}\text { Evaluation of } \\
\text { the students }\end{array}$ & $\begin{array}{l}\text { Evaluated by academic section including - } \\
\text { examination (lecture and seminar) } \\
\text { - dental staff evaluation (at GSP clinic) }\end{array}$ & $\begin{array}{l}\text { Evaluated by both academic and non-academic staff including } \\
\text { - examination (lecture and seminar) } \\
\text { - academic and non-academic staff evaluation (at GSP clinic and off-sites) }\end{array}$ \\
\hline
\end{tabular}

